\title{
SOBRE LA SUPUESTA INFLUENCIA DE LA INDEPENDENCIA DE LOS ESTADOS UNIDOS EN LAS INDEPENDENCIAS HISPANOAMERICANAS
}

\author{
POR
}

\author{
JAIME E. RODRÍGUEZ O. ${ }^{1}$
}

Universidad de California, Irvine

La independencia de Estados Unidos no infundió en los hispanoamericanos la idea de separarse de la Monarquía española. Sin embargo, su inacción no obedeció a la ignorancia. Por el contrario, numerosas obras impresas les proporcionaron información detallada sobre los acontecimientos ocurridos en Norteamérica. Ya desde la Guerra de los Siete Años, periódicos y publicaciones en lengua española mantenían al público informado sobre el descontento en las colonias del norte, el proceso de independencia y el establecimiento de un gobierno republicano. Más tarde, un acontecimiento sin precedentes -la invasión francesa a la Península española - transformaría el mundo hispánico. La expulsión del rey de España desencadenó una serie de acontecimientos que culminaron en la instauración de un gobierno representativo en aquella entidad política mundial y que, finalmente, resultaron en la disolución de la Monarquía española agregada. Así pues, la independencia de Estados Unidos y la de Hispanoamérica no sólo ocurrieron en distintos momentos, sino también bajo distintas circunstancias.

Palabras clave: Teoría política, Estados Unidos, independencia, naciones, guerras, publicaciones, constituciones, Hispanoamérica, comparaciones.

Las gentes de Sudamérica ${ }^{2}$ son las más ignorantes, las más intolerantes, las más supersticiosas de todos los católicos romanos de la Cristiandad... Ningún católico en la Tierra mostró devoción tan abyecta para con sus sacerdotes, superstición tan ciega como ellos... ¿Era acaso probable, era acaso posible que... un gobierno libre...

1 A Linda A Rodríguez y Mónica Quijada agradezco sus valiosas sugerencias para mejorar este trabajo.

${ }^{2}$ Las personas de habla inglesa se referían a Hispanoamérica — desde México hasta Chile- como Sudamérica. 
fuese introducido y establecido entre tales gentes, sobre tan vasto continente, o en cualquier parte de él? Me parecía... tan absurdo como... [lo] sería establecer democracias entre las aves, las bestias y los peces.

John Adams

Segundo Presidente de los Estados Unidos de América $^{3}$

¿Sabrá el Sr. ..., que nunca ha estado en las Américas, el despotismo que ejercen los ingleses en sus colonias, y la esclavitud en que éstas yacen?

Servando Teresa de Mier Teórico político mexicano ${ }^{4}$

Tras su independencia, Estados Unidos se convirtió en la nación más próspera del mundo. En tanto tal, ha gozado de un gobierno representativo estable y de éxito económico durante más de dos siglos. Resulta natural, por ende, creer que debe su éxito a su forma de gobierno. Un prominente historiador estadounidense, por ejemplo, afirmó hace poco que «la Revolución Estadounidense fue un acontecimiento de verdadera importancia global... Así, no sería exagerado decir que los orígenes de nuestro mundo moderno de estados pueden ser rastreados hasta la... Revolución Estadounidense» ${ }^{5}$. Estos argumentos se basan en la creencia de que el movimiento de independencia de Estados Unidos fue, no sólo el primero en fundar un Estado-nación exitoso, sino también el primero en postular los principios de libertad, autodeterminación y gobierno representativo. Tales presunciones son incorrectas.

La independencia de Estados Unidos proporcionó un apasionante ejemplo de transformación política, pero no constituyó un alejamiento radical respecto de la cultura política hispánica. El mundo hispánico, parte importante de la civilización occidental, abrevó en una cultura occidental compartida cuyos conceptos políticos se basaban en el pensamiento clásico antiguo y en las teorías medievales católicas. Este legado, junto con tres acontecimientos acaecidos en el siglo XVI, contribuyó a una notable transformación de la naturaleza del pensamiento político hispánico.

\footnotetext{
3 Adams, 1850-1856, vol. 10: 144-145.

4 Mier, 1988: 164.

5 Armitage, 2007: 138
} 
Durante los años de 1518 a 1521, una gran revolución política, la Rebelión de las Comunidades de Castilla, estalló en la Península española. Aprovechando la coronación del Rey Carlos I, que había sido criado en Flandes y tenía pocos lazos directos con Castilla, los representantes de las comunidades castellanas intentaron asumir el poder y establecer un nuevo orden constitucional. Dichos representantes formaron una Junta General de las Comunidades de Castilla, que perseveró en las ideas de que las ciudades representaban a la patria, el rey era su sirviente y de que poseían el derecho a elegir Cortes regularmente y a defender sus libertades por la fuerza de ser necesario. La Junta General también sostuvo que la voluntad del pueblo y el consentimiento de los gobernados debían reconocerse, e insistió no sólo en la libertad, sino también en la democracia. El movimiento, que ha sido llamado la primera revolución moderna, fue derrotado finalmente por las fuerzas de la Corona en la batalla de Villalar, el 23 de abril de 1521. A partir de entonces, las Cortes continuaron funcionando de manera tradicional. No obstante, tres siglos después, la rebelión se convertiría en el mito fundacional de los revolucionarios de las Cortes de Cádiz'.

La Reforma protestante del siglo XVI también contribuyó a la difusión del concepto de soberanía popular entre los teóricos políticos hispánicos. Cuando Martín Lutero postuló el principio del derecho divino de los príncipes con el fin de rechazar reivindicaciones similares por parte del papado, los teóricos católicos de la Escuela de Salamanca respondieron a los argumentos luteranos postulando el principio de la potestas populi (la soberanía del pueblo). Francisco Suárez refutó directamente las afirmaciones de Lutero sobre el derecho divino de los príncipes. Suárez y otros como Francisco de Vitoria, Diego de Covarrubias, Domingo de Soto, Luis de Molina, Juan de Mariana y, sobre todo, Fernando Vázquez de Menchaca, «ayudaron a fundar los cimientos para las así llamadas teorías del "contrato social” del siglo XVII ... [Además, el] jesuita Mariana ... [postuló] una teoría de la soberanía popular que, con orígenes escolásticos y calvinista en sus últimos desarrollos, era en esencia independiente de credos religiosos y estaba disponible por ende para ser usada por ambos bandos.... $\rangle^{7}$. Como lo ha mostrado el gran historiador inglés Quentin Skinner, los teóricos neoescolásticos hispánicos proporcionaron «un gran arsenal de armas ideológicas dis-

\footnotetext{
6 Maravall, 1963.

7 Skinner, 1978, vol. 2: 159, 347. Quijada, 24/ 2 (Berkeley, 2008b): 185-219.
} 
ponibles para ser aprovechadas por los revolucionarios...» de periodos posteriores ${ }^{8}$.

Más tarde, las provincias o estados de los Países Bajos se apoyarían en estas y otras teorías políticas para desafiar la autoridad del Rey de la Monarquía española, Felipe II. En 1579, dichos estados firmaron el Tratado de Utrecht, por medio del cual se convirtieron en «estados unidos» y accedieron a cooperar entre sí en su repudio a impuestos más altos, a la persecución de los protestantes y a la eliminación de sus estructuras medievales de gobierno representativo. Después, en 1581, esos mismos estados expidieron su Acto de Abjuración, su declaración de independencia frente a Felipe II. Más adelante, en 1588, establecieron la República holandesa. Naturalmente, aquellos insurgentes justificaron su revuelta contra el rey —a quien habían jurado lealtad-, en numerosos tratados que defendían su derecho a la autodeterminación, a la libertad religiosa y al gobierno representativo 9 .

Las ideas generadas por estos tres importantes acontecimientos, y por otros que más adelante tendrían lugar en los países protestantes, en Italia y en Francia, fueron reinterpretadas en las universidades y colegios de España y América y proporcionaron la base para el pensamiento político hispánico moderno. Entre los conceptos postulados por los comentaristas jurídicos de los siglos XVI y XVII, como Fernando Vázquez de Menchaca y Francisco Suárez, dos cobrarían relevancia a principios del siglo XIX: el principio de la soberanía popular (potestas populi) y la noción de un pacto (pactum translationis) entre el pueblo y el rey ${ }^{10}$. Las teorías de gobierno basadas en el derecho natural también serían ampliamente aceptadas en el mundo hispánico. Por ejemplo, Joaquín Marín y Mendoza, designado por Carlos III como titular de la cátedra de Derecho en San Isidro, publicó su Historia del derecho natural y de gentes en 1776. Marín y Mendoza, así como otros profesores de Derecho, introdujeron a sus estudiantes a varios autores europeos que desarrollaron teorías de gobierno basadas en el derecho natural y en el contrato social, entre ellos Gaetano Filangieri, Christian Wolf, Emmerich de Vatel y Samuel Pufendorf. Fueron estos autores menores, antes que el famoso Jean-Jacques Rousseau, quienes prepararon a varias generaciones de estudiantes hispánicos para reinterpretar la relación entre el pueblo y el gobierno ${ }^{11}$.

La redefinición de la relación entre pueblo y gobierno abarcaba lo mismo la esfera económica que la política. Tal fue el caso del pensamiento político

8 Skinner, 1978, vol 2: 114.

9 Israel, 1995. van Gelderen, 1992.

10 Suárez, 1918. Stoetzer, 1979. Quijada, 2005: 61-86. Quijada, 2008: 19-51.

11 Herr, 1958: 172-183. Chiaramonte, 2002: 99-122. 
hispánico, en el que las teorías económicas evolucionaron de manera paralela a las ideas en los países protestantes, en Italia y en Francia. Durante el reinado de Carlos III (1759-1788) varios distinguidos reformadores de la Monarquía española descartaron el mercantilismo a favor del libre comercio como un medio para promover el crecimiento económico. Su trabajo culminó en las actividades del gran economista y estadista Gaspar Melchor de Jovellanos. En 1774, antes de que Adam Smith publicara La riqueza de las naciones, Jovellanos expresó una opinión legal favoreciendo el libre comercio: «Quisiéramos restituir del todo la libertad, que es el alma del Comercio, la que da a las cosas comerciales aquella estimación que corresponde a su abundancia o escasez, y la que fija la justicia natural de los precios con respecto a la estimación de las cosas...». Tanto en sus acciones políticas como en sus obras publicadas más tarde, Jovellanos buscó eliminar el privilegio y fomentar la libertad comercial y política. Jovellanos afirmaba: «[El] primer principio político... aconseja dejar a los hombres la mayor libertad posible, a cuya sombra crecerán la industria, el comercio, la población y la riqueza» ${ }^{12}$. Durante su larga y destacada carrera, Jovellanos abogó por el libre comercio y atacó el privilegio, se opuso a la intervención del gobierno en la economía, y defendió los derechos de la propiedad individual y del interés. Desde su punto de vista, el papel del gobierno era fomentar la libertad económica, protegiendo los intereses y la propiedad privados, así como promover el desarrollo económico proporcionando infraestructura social y económica bajo la forma de educación, carreteras, canales, irrigación, puertos y otras instalaciones ${ }^{13}$.

\section{NOTICIAS DE TODAS LAS GUERRAS}

Los cambios radicales en el pensamiento político y económico del siglo XVIII ocurrieron dentro del contexto de un siglo de guerra en Europa. Una dimensión importante de la guerra fue el enfrentamiento entre las monarquías británica y española en cuatro ocasiones: la Guerra de Sucesión española (1700-1714); la Guerra de la Oreja de Jenkins (1739-1740); la Guerra de Sucesión Austriaca (1740-1748); y la Guerra de los Siete Años (1756-1763), que resultó desastrosa para la Monarquía española ${ }^{14}$. En dichos conflictos, los británicos intentaron controlar el comercio en los océanos Atlántico y Pacífico y obtener nuevos territorios en el Nuevo Mundo.

12 Citado en Polt, 1964: 25.

13 Ibid., 15-43.

14 Archer, 2008: 239-275. Frost, 1999: 33-52. 
Aún en la estela de la Guerra de los Siete Años, el continente americano pasó por una transformación significativa, cuando la Corona española y también la británica reestructuraron sus posesiones americanas, un proceso que en el mundo hispánico fue conocido como las Reformas Borbónicas. Aunque tanto españoles como americanos se opusieron a muchos de los cambios, los reinos españoles del Nuevo Mundo no imitaron a sus hermanos del norte rebelándose contra la Corona. Lejos de ello, la Monarquía española confiaba lo suficiente en sus súbditos americanos como para enfrentar a Gran Bretaña durante las guerras británico-americanas y firmar el Tratado de París en 1783, que reconocía la independencia de Estados Unidos. Es cierto que los hispanoamericanos se oponían a ciertos aspectos de las Reformas Borbónicas, y en ocasiones con violencia, pero no buscaban la separación respecto de la Corona española. Sólo cuando la Monarquía española cayó en 1808, resultado de la invasión francesa a la Península ibérica — treinta y dos años después de que se rebelaran los británicos americanos - los hispanoamericanos insistieron en tener un gobierno propio ${ }^{15}$.

La independencia de Estados Unidos no influyó en los hispanoamericanos como para que éstos se separaran de la Monarquía española. Pero si no actuaron, ello no se debió a la ignorancia. Todo lo contrario: numerosas obras publicadas les proporcionaron información detallada sobre los acontecimientos en América del Norte ${ }^{16}$. Desde 1763, la Gaceta de Madrid y el Mercurio Histórico y político, que circulaban ampliamente en el mundo hispánico, informaron sobre los resultados de la Guerra de los Siete Años y proporcionaron detalles sobre el tratado que puso fin al conflicto. En años posteriores, esos mismos periódicos ofrecieron largas crónicas sobre el descontento en las colonias británicas de Norteamérica, sobre la revuelta del Cacique Pontiac y la reacción del público ante las reformas británicas como la Ley del Azúcar y la Ley del Timbre. Ambas publicaciones dedicaron un espacio considerable a las Leyes Townshend, que restringían la autoridad de las asambleas locales e incrementaban los impuestos sobre diversos bienes. Los lectores de la Gaceta de Madrid y del Mercurio Histórico y político tuvieron noticia de la «Fiesta del Té» de Boston, en la que los ciudadanos de aquel puerto rehusaron a pagar más impuestos sobre el té, se vistieron de indios, abordaron los barcos del puerto y arrojaron el contenido al agua. Los periódicos también brindaron información detallada sobre el surgimiento de grupos que se oponían a la autoridad real británica en esas colonias. Ambos periódicos, pero en especial la Gaceta de Ma-

15 Grafenstein Gareis, 1997: 113-167. Chávez, 2002.

16 Butel-Dumont, 1768. 
drid, explicaron con detalle la instauración del Congreso Constitucional y la Declaración de Independencia del 4 de julio de 1776. Ambos señalaron que el Congreso había vacilado al considerar la separación respecto de la Corona británica, pero que un panfleto titulado Sentido común puso fin a las dudas. Algunos fragmentos de dicha publicación aparecieron en la Gaceta de Madrid, que erróneamente atribuyó la autoría del texto a «Mr. Adams uno de los Diputados del Congreso.... ${ }^{17}$.

Después de que España entrara en guerra con Gran Bretaña en 1778, los periódicos de Madrid publicaron informes detallados sobre la lucha de Estados Unidos por la independencia ${ }^{18}$. Ese mismo año, Francisco Álvarez publicó un relato de la historia, el gobierno y las costumbres de los británicos americanos ${ }^{19}$. Más adelante, apareció en la prensa de Madrid una traducción al español de la segunda Constitución de Estados Unidos de 178720. En 1783, José de Covarruvias publicó Memorias históricas de la última guerra contra la Gran Bretaña, desde el año de 1774: Estados Unidos de América, que proporcionó mucha información sobre los estados recién formados ${ }^{21}$. El interés en el conflicto y en la formación de Estados Unidos no disminuyó. Durante los años de 1786 a 1789, Antonio de Alcedo y Bejarano, natural de Quito, publicó un Diccionario Geográfico de las Indias Occidentales o América en cinco volúmenes. El Diccionario, que circuló ampliamente en España y América, era en esencia una enciclopedia sobre el continente americano. Además de la información geográfica sobre los estados y las ciudades principales de Estados Unidos, presentaba un largo relato de las causas y los procesos de independencia. Alcedo incluía una proclama de 1774 que él mismo tradujo, y que incitaba a los habitantes de Boston a tomar las armas contra el brutal gobierno británico. La proclama terminaba con el siguiente exhorto: «Despertad, americanos, nunca se vio la región que habitáis cubierta con tan espesas nubes. Se os llama rebeldes porque os negáis a pagar el tributo; pues bien, justificad vuestras pretensiones con vuestro valor, o sellad la pérdida con vuestra sangre ${ }^{22}$. Estas impetuosas palabras, empero, no llevaron a los hispanoamericanos a rebelarse.

17 García Melero, 1977: cita en la pág. 295.

18 Guardia Herrero, 27 (Madrid, 2001): 35-67.

19 Álvarez, 1778.

20 Según Carmen de la Guardia: «La Revolución americana fue una revolución colonial que no podía servir de ejemplo a una vieja metrópoli como España. Por eso, los textos revolucionarios circularon en Madrid sin problemas y además produciendo un verdadero interés en el monarca [Carlos III] y sus ministros....», Revista de Estudios Politicos, 93 (Madrid, 1996): 215.

21 Covarruvias, 1783. García Melero, 1977. Rodríguez, 1976.

22 Alcedo y Bexarano, 1786-1789: cita 2, 104-105. Lerner, 1971: 71-93. 
En 1806, en un momento en que la Monarquía española se había convertido en un satélite del Imperio francés y, por lo tanto, en un enemigo de Gran Bretaña, la Imprenta Real de Madrid publicó la Historia de la administración del Lord North, Primer Ministro de Inglaterra, y de la Guerra de la América Septentrional hasta la paz. La edición en lengua inglesa, publicada en Dublín, era crítica para con el gobierno británico y favorable a los americanos británicos. Una edición francesa posterior, sin embargo, glorificaba la Revolución estadounidense. Puesto que la edición en lengua española fue traducida del francés, también asumió una interpretación extremadamente positiva de la independencia de Estados Unidos. El gobierno de la Monarquía española, empero, no parece haberse preocupado por el impacto que dicha publicación pudiera tener sobre sus reinos del Nuevo Mundo ${ }^{23}$.

Las obras citadas anteriormente no son sino un ejemplo de los muchos materiales publicados en torno a la independencia de Estados Unidos y accesibles a los habitantes de la América española. Con unas cuantas excepciones - como la conspiración de los venezolanos Manuel Gual y José María España, y las actividades del jesuita en el exilio Juan Pablo Viscardo y Guzmánexiste poca evidencia de que se registraran intentos serios de separarse de la Monarquía española. Las actividades de intelectuales como Antonio Nariño o Eugenio Espejo no parecen haber sido revolucionarias. Gran parte de la evidencia en su contra proviene de la paranoia de los funcionarios reales que crearon infidencias ahí donde no las había. Cabe recordar aquí la comparación que Martin Minchom hizo sobre las reacciones a la Revolución francesa en Quito y en Inglaterra, tierra del gobierno representativo. «Quito e Inglaterra siguieron exactamente el mismo ciclo: el debate ilustrado seguido de la reacción (incluida, en Inglaterra, la disolución de asociaciones voluntarias), que finalmente culminó en un clima de represión, denuncia y conspiraciones reales o imaginadas $»^{24}$.

\section{FRENTE A LA INVASIÓN, SOBERANÍA}

Ni la independencia de Estados Unidos ni la Revolución francesa persuadieron a los habitantes de la América española de cortar sus lazos con la Monarquía española. En cambio, un inesperado levantamiento transformó el mun-

23 Anónimo, 1782. Anónimo, 1784. Anónimo, 1806. «[Más tarde en] los debates constitucionales [en Cádiz]... el ejemplo [norte] americano era invocado, pero de forma escasa y muchas veces con algún calificativo peyorativo». Guardia, (Madrid, 1996): 215.

24 Minchom, 1994: 237. 
do hispánico. En 1808, los franceses invadieron España; el Emperador Napoleón llevó a la familia real a Francia con engaños, la obligó a abdicar en su favor y después cedió la Monarquía española a su hermano José. La expulsión de la familia real española en 1808 constituyó un fenómeno nuevo en el mundo hispánico, un fenómeno que amenazaba la legitimidad de la monarquía. El rey usurpador, José I, no tuvo aceptación porque representaba a los franceses ateos, cuyas acciones amenazaban los pilares mismos de la sociedad española: la Iglesia, representante de Dios en la Tierra, y el rey legítimo Fernando VII, representante de los derechos y las libertades hispánicos. Además, a diferencia de los cambios dinásticos anteriores, las Cortes nunca confirmaron esta transformación.

Aunque en España las elites gobernantes capitularon, los habitantes de la Península y del Nuevo Mundo se mostraron prácticamente unánimes en su rechazo a los franceses. La amenaza externa subrayó los factores que los unían: una fe, una monarquía, una cultura general y una sociedad en crisis. Se trataba de miembros de lo que pronto sería conocido como la Nación Española, una nación compuesta por la Península y los reinos de ultramar. Puesto que todas las regiones de la Monarquía española tenían la misma cultura política general, todos los grupos -incluidos los de América- justificaron sus acciones recurriendo a los mismos principios y a un lenguaje casi idéntico ${ }^{25}$. Los habitantes de ambas regiones abrevaron en conceptos comunes y buscaron soluciones parecidas a la crisis en proceso. Inspirados por los fundamentos legales de la Monarquía, la mayoría estaba de acuerdo en que, en ausencia del rey, la soberanía recaía sobre el pueblo, que tenía la autoridad y la responsabilidad de defender a la nación ${ }^{26}$.

Las noticias sobre los dramáticos acontecimientos en España - la abdicación de Carlos IV a favor de Fernando VII, el levantamiento de los habitantes de Madrid el 2 de mayo, la abdicación de la familia real en Bayona, el nombramiento de José Bonaparte como rey de la Monarquía española, y la creación de juntas locales de gobierno en la Península- llegaron a los puertos atlánticos de América en mayo, junio, julio y agosto de 1808. La situación desconcertaba tanto a las autoridades reales como a los habitantes. ¿Quién go-

25 Como ha apuntado Miguel Artola: «El resultado más trascendental de los sucesos que han tenido por escenario a España entera y por protagonistas a todos los españoles, es el sentimiento de reasunción de la soberanía del pueblo, puesto de relieve en todos los escritores del momento». Artola, 1968: 68.

26 Sobre los principios hispánicos de la soberanía del pueblo, retroversión de la soberanía, y derecho de resistencia, véanse los trabajos de Quijada, 2005. Quijada, 2008a. Quijada, 24/2 (Berkeley, 2008b): 185-219. 
bernaba la Monarquía española? ¿A quién, de haberlo, debía obedecerse? ¿Qué se debía hacer?

En 1808, los habitantes de América respondieron a la crisis de la Monarquía con gran patriotismo y determinación. Los americanos de todas las razas y clases se mostraron unánimes en su expresión de lealtad a Fernando VII, en su oposición a Napoleón y en su determinación a defender su fe y sus patrias frente a la dominación francesa. La gente reconoció a Fernando VII como su legítimo y amado rey, rechazó a Napoleón, contribuyó con fondos para apoyar la guerra en la Península y se preparó para defender a la nación ante los opresores franceses. Durante este tiempo de crisis, la religión jugó un papel importante. Los habitantes de la América española organizaron oraciones públicas, misas formales y Te Deums en nombre del rey y de la nación ${ }^{27}$.

En la Península, las juntas — formadas originalmente para gobernar sus provincias y oponerse a los franceses - establecieron una Junta Suprema Central que se reunió el 25 de septiembre de 1808 para gobernar a la nación y coordinar la lucha contra los invasores. El 22 de enero de 1809, la Junta Central decretó que cada uno de los diez reinos de América y Asia - los virreinatos de Nueva España, Nueva Granada, Perú y Río de la Plata, las capitanías generales de Puerto Rico, Cuba, Guatemala, Venezuela, Chile y Filipinas- elegirían a un diputado para representarlos en el gobierno nacional $^{28}$.

Al tiempo que los americanos organizaban elecciones a la Junta Central, los franceses renovaban su campaña para conquistar la Península. Los ejércitos franceses volvieron a ocupar Madrid y durante 1809 y 1810 derrotaron a las fuerzas españolas a lo largo y ancho del país. Las noticias sobre estas calamidades alarmaron a los americanos, muchos de quienes creían que la Monarquía española no sobreviviría como una entidad independiente. También les preocupaba que las autoridades de España entregaran América a los franceses. No resulta sorprendente, entonces, que en 1809, al mismo tiempo que elegían a sus representantes ante la Junta Central, estallaran movimientos a favor de la autonomía en los dos reinos sudamericanos a los que no les fue concedida la representación individual ante la Junta por tratarse de audiencias subordinadas: Charcas, en mayo y julio, y Quito, en agosto de 1809. Estos movimientos fueron reprimidos, pero el clima de miedo influyó profundamente en las acciones subsiguientes del Nuevo Mundo. De hecho, en Quito se creía que la acción era necesaria porque, según se declaró, la Junta Central estaba

27 Rodríguez, O., 2005a: 102-118. Chust, 2007.

28 Rodríguez, O., 61 (México, 2005a): 6-32. 
«extinguida» ${ }^{29}$. Dicho organismo, incapaz de detener a los franceses, entregó el poder a una Regencia encargada de convocar elecciones a Cortes.

Las elecciones para formar un gobierno representativo en el mundo hispánico fueron llevadas a cabo en medio de una crisis de confianza. Para 1810 , la mayoría de los americanos pensaba que los franceses saldrían victoriosos. Después de todo, los ejércitos napoleónicos controlaban la mayor parte de la Península. El miedo a la dominación francesa fortaleció el deseo de buscar la autonomía en gran parte del Nuevo Mundo. En 1810, los movimientos autonomistas resurgieron en Charcas y Quito y estallaron en otros reinos: Caracas, en abril; Buenos Aires y Charcas, en mayo; Santa Fe de Bogotá, en julio; y tres regiones en septiembre - el Bajío en Nueva España, el día 16; Santiago de Chile el 18; y Quito el 20-. Todas estas regiones querían establecer gobiernos provisionales para gobernar en nombre del Rey Fernando VII. Inadvertidamente, los movimientos autonomistas de 1810, a diferencia de los de 1809, desataron otras fuerzas sociales. Grupos y áreas descontentos capitalizaron la oportunidad para que se atendieran sus denuncias. En poco tiempo, las guerras civiles consumían vastas extensiones del continente americano ${ }^{30}$.

La instauración de gobiernos autónomos ocasionó un debate generalizado. El discurso público ya se había intensificado después de 1808. La prensa escrita, que se convirtió en un instrumento indispensable de la política, alimentó una explosión de actividad en todo el mundo hispánico. En los meses y años que siguieron, avisos importantes - particularmente sobre los debates en las Cortes-, decretos, leyes, minutas de juntas especiales, informes sobre las elecciones, declaraciones de personas importantes y otras cuestiones de interés, se publicaron con presteza. Las noticias de Europa, Estados Unidos y otras regiones del Nuevo Mundo circularon ampliamente en las ciudades capitales y en los pueblos de provincias. Al tiempo que formaban sus nuevos gobiernos, los líderes de las diversas regiones de la América española discutieron la utilidad de los modelos estadounidense, británico y francés, así como los de siglos anteriores, incluida la república holandesa, las ciudades-estado italianas y las antiguas Grecia y Roma. No obstante, la abrumadora mayoría prefería las tradiciones y prácticas hispánicas. El proceso de independencia de la América española no constituyó un movimiento anticolonial, como muchos afirman, sino que formó parte tanto de una revolución dentro del mundo hispánico como de la disolución de la Monarquía española. A decir verdad, España fue una de las

29 Rodríguez, O., 2005a: 118-135.

30 Ibid., 197-297. 
nuevas naciones que surgió de la desintegración de aquella entidad política mundial.

\section{¿INFLUENCIA A POSTERIORI?}

Es cierto que los textos de prominentes figuras del movimiento de independencia de Estados Unidos estaban traducidos y habían aparecido en publicaciones españolas antes de 1810, pero las obras principales señaladas por los investigadores que creen que la influencia estadounidense fue capital aparecieron más tarde ${ }^{31}$. En muchos casos, los estudiosos de este tema se basan en similitudes de fraseo como evidencia del influjo. Tales aseveraciones ignoran las distintas condiciones domésticas que dieron pie al movimiento de independencia en Estados Unidos y a los primeros movimientos autonomistas en la América española. Y lo que es aún más importante: también desestiman el hecho de que un análisis de contenido de un gran número de panfletos publicados en la América española durante el periodo no demuestra un impacto significativo de las publicaciones estadounidenses en el amplio debate. Por su parte, un análisis de los debates dentro de las juntas y más adelante las asambleas constituyentes desvela únicamente referencias fugaces al modelo estadounidense.

Una revisión de las obras seleccionadas por quienes insisten en la influencia estadounidense demuestra sus limitaciones. En 1810, el venezolano José Manuel Villavicencio tradujo y publicó en Filadelfia la segunda Constitución de Estados Unidos, la Carta de 1787. Si bien no ha sido descubierta ninguna copia de su panfleto en la América española, cinco páginas de aquella obra aparecieron en la Gazeta de Caracas y más tarde en el Aviso al público. Solamente apareció en esos periódicos. Después, el 11 de enero de 1811, el Diario político de Santafé de Bogotá anunció que la traducción de Villavicencio estaba en venta por tres reales ${ }^{32}$. Quizás circularon otras copias en otras partes de la América española. Por ejemplo, una copia manuscrita de la Constitución de 1787 fue encontrada en Río de la Plata, aparentemente traducida por un comerciante inglés de Buenos Aires, de nombre McKinnon ${ }^{33}$. Estos casos resultan interesantes, pero no demuestran nada acerca de la influencia que dicho documento pudo haber tenido en aquellos dos países.

31 Simmons, 1992. Soto Cárdenas, 1979.

32 Villavicencio, 1810. Simmons, 1992: 138-141.

33 Simmons, 1992: 196-201. 
La Constitución venezolana de 1811 estableció un sistema federal, como lo hiciera Estados Unidos, pero ambos documentos constituían respuestas a situaciones domésticas distintas. En Estados Unidos, la Constitución de 1787 establecía un gobierno más fuerte que los anteriores Artículos de la Confederación. En contraste, las provincias de Venezuela, siguiendo la tradición hispánica establecida, enfatizaron el derecho al gobierno local. Además, destacados venezolanos como el prominente jurista Fernando Peñalver, fueron muy críticos con la Constitución de $1787^{34}$. Aun cuando existían ciertas similitudes, también se registraban muchas diferencias significativas entre ambos documentos: la Constitución de Estados Unidos no mencionaba la religión, mientras que la de Venezuela reconocía: «La Religión, Católica, Apostólica, Romana, es también la del Estado y la única exclusiva de los habitantes de Venezuela». La Carta estadounidense otorgaba una considerable autoridad al poder ejecutivo, ya que establecía un sistema presidencial, mientras que la Constitución venezolana concedía el poder a la legislatura y fundaba un débil triunvirato. La Constitución de Estados Unidos equilibraba la representación asignando a cada estado dos senadores, sin importar el grueso de su población. El Artículo 45 de la Carta venezolana, empero, mantenía la representación proporcional en el Senado asignando «un número de individuos, cuya proporción no pasará de la tercera, ni será menos de la quinta parte de los [diputados de la Cámara de] Representantes». La Constitución de Venezuela era mucho más detallada y extensa que el documento estadounidense ${ }^{35}$. Éstas son sólo algunas de las numerosas diferencias que existían entre las dos constituciones. El sistema que los venezolanos confeccionaron reflejaba las realidades venezolanas, y no un modelo abstracto.

También se suele creer que la Constitución mexicana de 1824 se basó en la Carta estadounidense. No existen pruebas de tal influjo. Es cierto que ambas son constituciones federales. Sin embargo, México se convirtió en una república federal porque sus líderes en las Cortes de Cádiz, como Miguel Ramos Arizpe, habían introducido gobiernos de provincias en la Constitución de 1812. Más adelante, esos gobiernos, llamados Diputaciones Provinciales, se convirtieron en la base para los estados de la República Federal independiente de México. Un análisis de los debates del Congreso Constituyente de 1823 indica que la Constitución estadounidense de 1787 prácticamente no tuvo influencia alguna sobre la Carta mexicana ${ }^{36}$.

34 Peñalver, 1961, vol. 2: 25-39.

35 Venezuela, 1983. Hébrard, 1998: 196-224.

36 Benson, 1955. 
Otro venezolano, Manuel García de Sena, quien también publicó en Filadelfia obras que podrían haber circulado en toda Sudamérica, es considerado por los que desean demostrar la influencia estadounidense como la persona que introdujo una influyente obra titulada La independencia de la Costa Firme justificada por Thomas Paine treinta años ha, que apareció en 1811. Al año siguiente, apareció una segunda publicación considerada importante: Historia concisa de los Estados Unidos desde el descubrimiento de América hasta el año de $1807^{37}$. Al parecer, estas obras circularon en las ciudades porteñas de Sudamérica. Sin embargo, su influencia no resulta evidente. Venezuela, por ejemplo, declaró la independencia en julio de 1811, antes de la llegada del primer volumen justificando la independencia estadounidense. Un análisis de los debates del Congreso de dicha nación no proporciona indicación alguna de la influencia de dicho volumen. Además, los argumentos de Paine tenían poco que ver con la realidad venezolana. El territorio sudamericano estaba más preocupado por la dominación francesa de la Monarquía española que por las quejas contra sus gobernantes ${ }^{38}$.

\section{MisMAS FRASES, DISTINTOS CONTEXTOS}

Quienes desean demostrar la influencia de Estados Unidos sobre la independencia de la América española suelen recurrir a la similitud del lenguaje entre documentos estadounidenses y algunos textos escritos por hispanoamericanos. El ejemplo favorito de todos es la Declaración de Independencia escrita por Thomas Jefferson. Vale la pena reiterar que la primera declaración formal de independencia fue escrita por los holandeses en 1581. De hecho, al leer el documento estadounidense, William V, príncipe de Orange, lo consideró «una parodia de la proclama emitida por nuestros fundadores contra el Rey Felipe II $»^{39}$. Aun cuando la declaración estadounidense no fue la primera, ciertamente era un documento espléndido, cuyas frases fueron adaptadas para su uso en otros contextos. Dos ejemplos provenientes de los extremos del continente servirán a nuestros propósitos.

En agosto de 1810, Mariano Moreno, secretario de la Junta Provisional de la Capital del Río de la Plata, hizo la siguiente declaración:

37 García de Sena, 1811. García de Sena, 1812.

38 Para una interpretación diferente de la mía véase: Grases y Harkness, 1953. Véase también: Leal Curiel, 31/40 (Caracas, 2008): 1-18.

39 Citado en Armitage, 2007: 43. 
Quando en el curso de los sucesos humanos se ve presisado un pueblo a romper los vinculos que los ligaban a otro, es un deber de justicia, que por respeto a las opiniones de los demas hombres, se manifiesten los motivos que han conducido a esta separación. La Capital de Buenos Ayres, inseparable de las medidas de moderacion que se ha propuesto, tentó todos los medios legítimos de unirse estrechamente a Montevideo... ${ }^{40}$

Aquí, un fraseo similar fue utilizado para abordar dos situaciones radicalmente diferentes. En este caso, Buenos Aires intentaba dominar todo el Virreinato del Río de la Plata, y Montevideo, como otras provincias, no estaba dispuesto a ceder el poder a los porteños. Moreno plagió a Jefferson por su brillante escritura, y no porque el documento original lo alentara a buscar la independencia respecto de la Monarquía española.

El segundo ejemplo proviene de Béjar, Texas, que declaró su independencia el 6 de abril de 1813. En este caso, los autores desconocidos del documento parafrasearon la última parte de la declaración estadounidense de independencia de la siguiente manera:

Nos el Pueblo de la provincia de Texas jurando al Juez Supremo del universo la rectitud de nuestras intenciones, declaramos que los vínculos que nos mantenían bajo de la dominación de España europea están por siempre disueltos, que somos libres e independientes; que tenemos el derecho de establecer nuestro propio gobierno; y que en adelante toda autoridad legítima dimanará del pueblo, a quien solamente pertenece este derecho; que desde ahora siempre jamás estaremos absueltos de deber y obligaciones a todo poder extranjero ${ }^{41}$.

En este caso, los británicos americanos participaron en el movimiento para separar a Texas del Virreinato de Nueva España y anexarlo a Estados Unidos. Sus planes no funcionaron en aquel momento. Pero lo harían veintitrés años más tarde.

La Declaración de Independencia de Estados Unidos y otros documentos eran bien conocidos en el mundo hispánico. Sin embargo, no eran textos únicos ni constituyeron la causa del proceso de independencia de la América española. Los líderes de Estados Unidos habían seguido ellos mismos tradiciones anteriores. Cuando llamaron «estados» a sus provincias, seguían la tradición holandesa. Además, su primera constitución, los Artículos de la Confederación, también abrevaba en la experiencia holandesa. La segunda Carta de Estados Unidos, la Constitución de 1787, provenía en parte de la tradición romana antigua con su Senado, y su asamblea popular, la Cámara de Representantes. También se fundaba en la práctica inglesa, con su Cámara de los Lores

40 Citado en Simmons, 1992: 191-192.

41 Citado en Guedea, 2001: 163-164. 
y su Cámara de los Comunes. Esto no quiere decir que los Padres de la Patria en Estados Unidos se limitaran a copiar prácticas antiguas. ¡Y no lo hicieron! Adaptaron documentos anteriores a sus circunstancias. Eso es lo que los habitantes del mundo hispánico hicieron también. Así como sus hermanos británico americanos se apoyaron principalmente en fuentes inglesas, los dirigentes de la América española se apoyaron sobre todo en sus tradiciones hispánicas.

Aquí resulta útil recordar las palabras del gran teórico político mexicano Servando Teresa de Mier, quien declarara en el Congreso Constituyente mexicano de 1823:

Los Estados Unidos no se constituyeron hasta concluida la guerra con la Gran Bretaña ... ¿Y con qué se rigieron mientras? Con las máximas heredadas de sus padres: y aun la constitución que después dieron no es más que una colección de ellas ... ¿Y mientras con qué nos gobernamos? con lo mismo que hasta aquí, con la constitución española, las leyes que sobran en nuestros códigos no derogados, los decretos de las Cortes Españolas hasta el año 1820 y las del Congreso [mexicano] que ha ido e irá modificando todo esto conforme al sistema actual y a nuestras circunstancias $^{42}$.

\section{DISTINTOS MOMENTOS, DISTINTOS DESTINOS}

La independencia de Estados Unidos influyó poco sobre la independencia de la América española, pero la federación del norte les resultó muy atractiva a las nuevas naciones. Si bien algunos líderes políticos, como Vicente Rocafuer$t^{43}$, alabaron su forma de gobierno, en realidad era su riqueza y su estabilidad lo que atraía a los hispanoamericanos. Éstos creían que la independencia de sus países y la instauración de gobiernos representativos en ellos conducirían inevitablemente a una prosperidad económica y a un orden político similar a los que gozaba Estados Unidos. Puesto que tal cosa no ocurrió, muchos observadores contemporáneos y estudiosos actuales concluyeron que los fracasos de las nuevas naciones hispanoamericanas eran imputables a su falta de prepa-

42 Mier, 1984, vol. 2, tomo 1: 201-208.

43 Rocafuerte acogió favorablemente la Constitución de Cádiz. Sin embargo, el fracaso subsiguiente de las Cortes españolas en 1822 y 1823 lo obligó - junto con muchos otros liberales hispanoamericanos - a adoptar una nueva visión de la comunidad hispanoamericana. En este proceso, Rocafuerte publicó varias obras alabando el republicanismo y utilizando a Colombia, pero especialmente a Estados Unidos, como modelo para las nuevas naciones. Véanse, por ejemplo, sus volúmenes: Rocafuerte, 1821. Rocafuerte, 1822. Rocafuerte, le dijera a su amigo Carlos María de Bustamante: «es necesario que ustedes se desengañen [de la idea] de que el gobierno de Norte América no es enemigo del de México». (12 de abril de 1830), Bustamante, 2001. Rodríguez O., 2007. 
ración para un gobierno autónomo y a la adopción de modelos políticos extranjeros inapropiados. Pero esto no es correcto, nuevas investigaciones demuestran que los habitantes de la Monarquía española contaban con amplia representación y estaban bien preparados para el gobierno autónomo. De hecho, la gran revolución política comenzó cuando la Constitución de Cádiz otorgó a los habitantes de la América española una amplia experiencia en la elección de sus representantes a Cortes, Diputaciones Provinciales y Ayuntamientos Constitucionales. Además, la Constitución de 1812 estableció un sufragio más amplio que el de Gran Bretaña, Estados Unidos o Francia ${ }^{44}$.

¿Por qué, entonces, España y la América Española experimentaron una decadencia política y económica durante el siglo XIX? ¿Por qué no gozaron de una estabilidad y de un crecimiento económico continuo, como Gran Bretaña y Estados Unidos después de la emancipación de este último? Es una pregunta compleja a la que no puede darse una contestación monolítica; entre otras cosas porque los procesos no están predeterminados y se van configurando en largos espacios temporales. No obstante, es posible contribuir a su desvelamiento con algunas aportaciones. Por ejemplo, prestando atención a la propia naturaleza de la Monarquía española y al momento temporal en que se dio la independencia de la América española.

La independencia hispanoamericana no consistió únicamente en la separación respecto de la madre patria, como en el caso de Estados Unidos; también destruyó un vasto y receptivo sistema social, político y económico que funcionaba bien pese a sus muchas imperfecciones. La Monarquía española mundial había demostrado ser flexible y capaz de contener las tensiones sociales e intereses políticos y económicos encontrados durante casi 300 años. En la época posterior a la independencia, se hizo evidente que, de manera individual, las antiguas partes de la Monarquía española se encontraban en desventaja competitiva. Es en ese sentido que la España decimonónica, al igual que su progenie americana, fue sólo una nación más, recién independizada, buscando a ciegas un lugar en un mundo desconcertante y complicado.

En contraste con Estados Unidos, que obtuvo su independencia en 1783, justo a tiempo para beneficiarse de la insaciable demanda de sus productos generada por los veinte años de guerra que siguieron a la Revolución francesa de 1789 en Europa, el mundo hispánico logró emanciparse después de las guerras europeas. Las nuevas naciones no sólo tuvieron que reconstruir sus economías devastadas, también se enfrentaron a la falta de demanda de sus productos. Di-

44 Quijada, LXVIII/242 (Madrid, 2008c): 15-38; Rodríguez O., 2005:155-196; Rodríguez O., 2005c. Rodríguez O., 2003. Rodríguez O., 2006. Rodríguez O., 2009. Dym, 2006. Peralta Ruiz, 2002. 
chas naciones no gozaron de prosperidad durante sus años de formación, como lo hizo Estados Unidos. En lugar de ello, los estados hispanoamericanos tuvieron que enfrentar graves problemas internos y externos con recursos cada vez menores.

La independencia de Estados Unidos, por otra parte, no derivó en la destrucción política y económica del mundo británico. Pese a algunos conflictos breves y relativamente menores, las relaciones culturales, económicas y diplomáticas entre la antigua metrópolis y la antigua colonia continuaron. Y lo que es aún más importante: durante el siglo XIX, Gran Bretaña se convirtió en la más grande potencia industrial, comercial, financiera, tecnológica y naval en el mundo. La historia de Estados Unidos habría sido considerablemente distinta si España hubiese alcanzado esta preeminencia al tiempo que Gran Bretaña se colapsaba. En un mundo dominado por un país con una lengua, una religión y una cultura diferentes, Estados Unidos habría sido menos privilegiado políticamente, menos capaz de explotar su rica dotación de recursos fácilmente accesibles y, lo que es más, habría tenido que competir con vecinos poderosos. Tal situación, por supuesto, no tuvo lugar. En cambio, Estados Unidos creció territorialmente a través de la conquista, se expandió económicamente y mantuvo un sistema político estable que se volvió cada vez más democrático.

No fue sino hasta el último tercio del siglo XIX que las naciones de América, así como España, comenzaron a consolidar sus estados. Para las décadas de 1870 y 1880, España y la mayor parte de los países hispanoamericanos habían establecido gobiernos estables y emprendido el difícil proceso de rehabilitación económica. Desgraciadamente, la antigua Monarquía española había languidecido durante cincuenta años cruciales en los que Gran Bretaña, Francia, Alemania y Estados Unidos avanzaron a un estadio distinto de desarrollo económico. En los años que pasaron desde que la gran revolución política disolviera la Monarquía española, el mundo del Atlántico Norte se transformó drásticamente. Las corporaciones industriales y las instituciones financieras de la Europa occidental y de Estados Unidos habían alcanzado tal fuerza y dimensión, que las economías emergentes de España e Hispanoamérica sencillamente no podían competir. En consecuencia, los miembros de la antigua Monarquía española se vieron forzados a aceptar un papel secundario en el nuevo orden mundial ${ }^{45}$.

45 Rodríguez O., 2005: 411-425. 


\section{BIBLIOGRAFÍA}

Adams, John, The Works of John Adams, 10 Vols. Boston, Little, Brown and Co., 1850-1856.

Alcedo y Bexarano, Antonio de, Diccionario geográfico de las Indias Occidentales o América: es á saber, de los reynos del Perú, Nueva España, Tierra Firme, Chile y Nuevo Reyno de Granada, 5 Vols., Madrid, Imprenta de Benito Cano, 1786-1789.

Anónimo, A view of the history of Great-Britain, during the administration of Lord North, to the second session of the fifteenth parliament. In two parts, Dublin, printed by P. Byrne, 1782.

Anónimo, Histoire de l'administration de Lord North ... et de la guerre de l'Amérique Septentrionale jusqu'a la paix: suivie du tableau historique des finances d'Angleterre depuis Guillaume III jusqu'en 1784, Paris, Chez l'auteur, 1784.

Anónimo, Historia de la administración del Lord North, Primer Ministro de Inglaterra, y de la Guerra de la América Septentrional hasta la paz. Obra escrita en inglés, traducida al francés, y de este al castellano, Madrid: la Imprenta Real, 1806.

Archer, Christon I., «Reflexiones de una edad de guerra total: El impacto de la defensa marítima de Nueva España en la época revolucionaria, 1789 a 1810», Manuel Chust y Juan Marchena, eds., Por la fuerza de las armas. Ejército e independencia en España e Hispanoamérica (1750-1850), Castellón, Universitat Jaume I, 2008: 239-275.

Armitage, David, The Declaration of Independence: A Global History Cambridge, Massachusetts, Harvard University Press, 2007.

Artola, Miguel, La España de Fernando VII, Madrid, Espasa-Calpe, 1968.

Benson, Nettie Lee, La diputación provincial y el federalismo mexicano, México, El Colegio de México, 1955.

Bustamante, Carlos María de, «Diario de lo especialmente ocurrido en México», Josefina Zoraida Vázquez y Héctor Cuauhtémoc Hernández Silva (eds.), Diario histórico de México, 1822-1848, CD-ROM, México, COLMEX/CIESAS, 2001.

Butel-Dumont, George Marie, Historia del establecimiento y comercio de las colonias inglesas en la América Septentrional: en que se da noticia del estado actual de su población, y algunas relaciones individuales y curiosas, acerca de la constitución de su gobierno, principalmente de la Nueva Inglaterra, de la Pensilvania, de la Carolina, y de la Georgia, Madrid, Joaquín Ibarra, 1768.

Chávez, Thomas E., Spain and the Independence of the United States, Albuquerque, University of New Mexico Press, 2002.

Chiaramonte, José Carlos, «Fundamentos iusnaturalistas de los movimientos de independencia», Marta Terán y José Antonio Serrano Ortega (eds.), Las guerras de in- 
dependencia en la América española, Zamora, El Colegio de Michoacán, 2002: 99-122.

Chust, Manuel, coord., La eclosión juntera en el mundo hispano, México, Fondo de Cultura Económica, 2007.

Covarruvias, José de, Memorias históricas de la última guerra con la Gran Bretaña, desde el año de 1774: Estados Unidos de América, Madrid, Imprenta de Antonio Ramírez, 1783.

Dym, Jordana, From Sovereign Villages to National States: City, State, and Federation in Central America, 1759-1839, Albuquerque, University of New Mexico Press, 2006.

Frost, Alan, «The Spanish Yoke: British Schemes to Revolutionise Spanish America, 1739-1807», Alan Frost y Jane Samson (eds.), Pacific Empires: Essays in Honor of Glynwr Williams Melbourne, Melbourne University Press, 1999: 33-52.

García Melero, Luis Ángel, La independencia de los Estados Unidos de Norte América a través de la prensa española, Madrid, Ministerio de Asuntos Exteriores, 1977.

García de Sena, Manuel, La independencia de la Costa Firme justificada por Thomas Paine treinta años ha. Extracto de sus obras, traducido del inglés al español por D. Manuel García de Sena, Filadelfia, imprenta de T. y J. Palmer, 1811.

García de Sena, Manuel, Historia de los Estados Unidos desde el descubrimiento de la América hasta el año de 1807, Filadelfia, imprenta de T. y J. Palmer, 1812.

Gelderen, Martin van, The Political Thought of the Dutch Revolt Cambridge, Cambridge University Press, 1992.

Grafenstein Gareis, Johanna von, Nueva España en el circuncaribe, 1779-1808: Revolución, competencia imperial y vínculos intercoloniales, México, Universidad Nacional Autónoma de México, 1997.

Grases, Pedro y Alberto Harkness, Manuel García de Sena y la independencia de Hispanoamérica, Caracas, Publicaciones de la Secretaría General de la Décima Conferencia Interamericana, 1953.

Guardia Herrero, Carmen de la, «La Revolución Americana y el Primer Parlamentarismo Español», Revista de Estudios Políticos, 93 (julio-septiembre 1996): 205218.

Guardia Herrero, Carmen de la, «Hacia la creación de la República Federal. España y los Estados Unidos: 1783-1789», Revista Complutense de Historia de América, 27 (2001): 35-67.

Guedea, Virginia, «Autonomía e independencia en la Provincia de Texas. La Junta de Gobierno de San Antonio de Béjar, 1813», Virginia Guedea (coord.), La independencia de México y el proceso autonomista novohispano, 1808-1824, México, Universidad Nacional Autónoma de México, 2001: 163-164. 
Hébrard, Veronique, «Opinión pública y representación en el Congreso Constituyente de Venezuela (1811-1812)», François-Xavier Guerra y Annick Lempérière (coords.), Los espacios públicos en Iberoamérica. Ambigüedades y problemas. Siglos XVIII-XIX, México, Fondo de Cultura Económica y Centro Francés de estudios mexicanos y centroamericanos, 1998: 196-224.

Herr, Richard, The Eighteenth Century Revolution in Spain, Princeton, Princeton University Press, 1958.

Israel, Jonathan I., The Dutch Republic: Its Rise, Greatness, and Fall, 1477-1806, Oxford, Clarendon Press, 1995.

Leal Curiel, Carole, «¿Radicales o timoratos? La declaración de la Independencia absoluta como una acción teórica-discursiva (1811)», Politeia, Revista de la Facultad de Ciencias Jurídicas y Políticas de la Universidad Central de Venezuela, 31/40 (2008): 1-18.

Lerner, I., «The Diccionario of Antonio de Alcedo as a source of Enlightened Ideas», Alfred Owen Aldridge (ed.), The Ibero-American enlightenment, Urbana, University of Illinois Press, 1971: 71-93.

Maravall, José Antonio, Las Comunidades de Castilla. Una primera revolución moderna, Madrid, Revista de Occidente, 1963.

Mier, Servando Teresa de, «Discurso que el día 13 de diciembre del presente año de 1823 pronunció el Dr. D. Servando Teresa de Mier Diputado por Nuevo León sobre el artículo 5. ${ }^{\circ}$ del Acta Constitutiva», Carlos María de Bustamante, Diario histórico de México (edición y notas de Manuel Calvillo), 3 vols. en 4 tomos, México, Instituto Nacional de Antropología e Historia, 1980-1984, vol. 2, tomo 1 (julio-diciembre de 1823): 201-208.

Mier, Servando Teresa de, «Memoria político-instructiva enviada desde Filadelfia en agosto de 1821 a los gefes [sic] independientes del Anáhuac, llamado por los españoles Nueva España», Jaime E. Rodríguez O. (ed.), La formación de un republicano, vol. 4, Obras completas, México, Universidad Nacional Autónoma de México, 1988.

Minchom, Martin, The People of Quito, 1690-1810: Change and Unrest in the Underclass, Boulder, Westview Press, 1994.

Peñalver, Fernando, «Memoria presentada al Supremo Congreso de Venezuela, en que manifiesta sus opiniones sobre la necesidad de dividir la provincia de Caracas para hacer la Constitución federal permanente; y los artículos con que cree deben ligarse las provincias para formar un solo estado y soberanía», Academia Nacional de Historia, Pensamiento constitucional hispano-américano. 5 vols, Caracas, Academia Nacional de Historia, 1961: V, 25-39.

Peralta Ruiz, Víctor, En defensa de la autoridad: política y cultura bajo el gobierno del virrey Abascal. Perú 1806-1816, Madrid, Consejo Superior de Investigaciones Científicas, 2002. 
Polt, John H. R., Jovellanos and His English Sources, Economic, Philosophical, and Political Writings, Filadelfia, Transactions of the American Philosophical Society, 1964.

Quijada, Mónica, «Las “dos tradiciones”. Soberanía popular e imaginarios compartidos en el mundo hispánico en la época de las grandes revoluciones atlánticas», Jaime E. Rodríguez O. (coord.), Revolución, independencia y las nuevas naciones de América, Madrid, Fundación MAPFRE-Tavera, 2005: 61-86.

Quijada, Mónica, «Sobre "Nación”, "Pueblo", "Soberanía” y otros ejes de la modernidad en el mundo hispánico», Jaime E. Rodríguez O. (coord.), La nuevas naciones: España y México, 1800-1850, Madrid, Instituto de Cultura-Fundación MAPFRE, 2008a: 19-51.

Quijada, Mónica, «From Spain to New Spain Revisiting the potestas populi in Hispanic Political Thought», Mexican Studies/Estudios Mexicanos, 24/2 (Berkeley 2008b), 185-219.

Quijada, Mónica, «Una Constitución singular, La Carta gaditana en perspectiva comparada», Revista de Indias, LXVIII: 242 (enero-abril 2008c): 15-38.

Rocafuerte, Vicente, Ideas necesarias a todo pueblo americano independiente que quiera ser libre, Filadelfia: D. Huntington, 1821.

Rocafuerte, Vicente, Bosquejo ligerísimo de la revolución de Megico [sic] desde el grito de Iguala hasta la proclamación imperial de Iturbide, Filadelfia, Imprenta de Terarouef y Naroajeb, 1822.

Rocafuerte, Vicente, Ensayo político. El sistema colombiano, popular, electivo, y representativo, es el que más conviene a la América Independiente, Nueva York, Imprenta de A. Paul, 1823.

Rodríguez, Mario, La revolución Americana de 1776 y el mundo hispánico: ensayos y Documentos, Madrid: Editorial Tecnos, 1976.

Rodríguez, O. y Jaime, E., «La naturaleza de la representación en la Nueva España y México», Secuencia: Revista de historia y ciencias sociales, 61 (enero-abril 2005a): 6-32.

Rodríguez, O. y Jaime, E., La independencia de la América española, 2. ${ }^{\text {a }}$ ed., México, Fondo de Cultura Económica, 2005 b.

Rodríguez, O. y Jaime, E. (ed.), Revolucion, independencia y las nuevas naciones de América, Madrid, Fundación MAPFRE \& Tavera, 2005c.

Rodríguez, O. y Jaime, E., La revolución política en la época de la independencia: El Reino de Quito 1808-1822, Quito, Universidad Andina Simón Bolívar y Corporación Editora Nacional, 2006.

Rodríguez, O. y Jaime, E., El nacimiento de Hispanoamérica: Vicente Rocafuerte y el hispanoamericanismo, 1808-1832, 2. ${ }^{\mathrm{a}}$ ed., Quito, Universidad Andina Simón Bolívar y Corporación Editora Nacional, 2007. 
Rodríguez, O. y Jaime, E., «Nosotros somos ahora los verdades españoles»: La transición de Nueva España de un reino de la Monarquía Española a la República Federal de México, 1808-1824, México \& Zamora, Instituto Mora \& El Colegio de Michoacán, 2009.

Simmons, Merle E., La Revolución norteamericana en la independencia de Hispanoamérica, Madrid, MAPFRE, 1992.

Skinner, Quentin, The Foundations of Modern Political Thought, 2 vols. Cambridge Cambridge University Press, 1978.

Soto Cárdenas, Alejandro, Influencia de la Independencia de los Estados Unidos en la Constitución de las Naciones Latinoamericanas, Washington, Organización de Estados Americanos, 1979.

Stoetzer, O. Carlos, The Scholastic Roots of the Spanish American Revolution. New York, Fordham University Press, 1979.

Suárez, Francisco, Tratado de las leyes y de Dios legislador, trad. Jaime Torrubiano Ripoll Madrid, Reus, 1918.

Villavicencio, Juan Manuel, Constitución de los Estados Unidos de América. Traducida del inglés al español por don Jph. Manuel Villavicencio, Filadelfia, en la imprenta de Smith y M'Kenzie, 1810.

Venezuela, Congreso Constituyente de 1811-1812, Caracas, Ediciones Conmemorativas del Bicentenario del Natalicio del Libertador Simón Bolívar, Congreso de la República, 1983.

Fecha de recepción: 21 de octubre de 2009

Fecha de aceptación: 7 de mayo de 2010 


\section{THE SUPPOSED INFLUENCE OF THE INDEPENDENCE OF THE UNITED STATES IN THE INDEPENDENCE OF SPANISH AMERICA}

The independence of the United States did not influence the Spanish Americans to separate from the Spanish Monarchy. Their failure to act did not stem from ignorance. On the contrary, numerous printed works provided them with detailed information about events in North America. Since the Seven years war Spanish language newspapers and publications kept the public informed about the discontent in the North American colonies, the process of independence, and the establishment of a republican government. Subsequently, an unprecedented event, the French invasion of the Spanish peninsula, transformed the Hispanic world. The ouster of the Spanish king triggered a series of events that culminated in the establishment of representative government in that world wide polity and eventually resulted in the dissolution of the composite Spanish Monarchy. Thus, the independence of the United States and of Spanish America occurred not only at different times, but also under different circumstances.

Key words: Political theory, United States, independence, nations, wars, publications, constitutions, Spanish America, comparisons. 